\title{
Development and maintenance of a specific pathogen-free (SPF) zebrafish research facility for Pseudoloma neurophilia
}

\author{
Michael L. Kent ${ }^{1, *}$, Cari Buchner ${ }^{2}$, Virginia G. Watral ${ }^{1}$, Justin L Sanders ${ }^{1}$, \\ Jane LaDu ${ }^{2}$, Tracy S. Peterson ${ }^{1}$, Robert L. Tanguay ${ }^{2}$ \\ ${ }^{1}$ Department of Microbiology, and ${ }^{2}$ Department of Environmental and Molecular Toxicology, Oregon State University, \\ Corvallis, Oregon, USA
}

\begin{abstract}
Pseudoloma neurophilia (Microsporidia) is very common in zebrafish Danio rerio research facilities. A new zebrafish facility has been established at the Sinnhuber Aquatic Resource Laboratory (SARL), Oregon State University, Corvallis, OR, USA, and this was an opportunity to establish a specific pathogen-free (SPF) colony of zebrafish for this microsporidium. Progeny from 9 zebrafish lines $(n=2203)$ were initially transferred to the SARL facility in 2007 following PCR screening of broodstock and a subpopulation of progeny (258 of 1000 fish from each family). Screening of fish for $P$. neurophilia within the facility was conducted as follows: (1) Moribund or dead fish were examined by histology. (2) Each line was regenerated on a 4 mo rotation, and a subsample of each of these major propagations (60 fry, in pools of 10) was PCR-screened at $10 \mathrm{~d}$ post hatch. (3) Adult fish ( 1 yr old) from each line were euthanized; 20 fish were examined by histology and the brains of another 60 fish (in pools of 5) were screened by PCR. (4) This screening was replicated on sentinel fish held in 4 tanks receiving effluent water from all tanks in the facility (20 fish per tank). (5) Fourmonth old fish $(n=760)$ from a toxicology study conducted within the laboratory were examined by histology. To date, we have evaluated 2800 fish by PCR and 1222 fish by histology without detecting $P$. neurophilia. Thus, we have established 9 lines of zebrafish SPF for P. neurophilia. However, 26 fish exhibited mycobacteriosis, with acid-fast bacteria present in tissue sections, and 49 other fish had incidental lesions.
\end{abstract}

KEY WORDS: Zebrafish $\cdot$ Disease control $\cdot$ Microsporidia

Resale or republication not permitted without written consent of the publisher

\section{INTRODUCTION}

A cornerstone for control of infectious diseases in laboratory animals, particularly with mice, is the use of animals that are specific pathogen free (SPF). The concept of working with SPF animals is gradually being accepted by laboratory researchers using zebrafish Danio rerio. Zebrafish research was first focused on developmental genetics using embryonic stages of the fish (Fishman 2001). Now they are used in post-embryonic stages in toxicology, immunology, transplant studies, infectious disease research, and as a platform for high throughput chemical screening (Sumanas \& Lin
2004, Traver et al. 2004, Zon \& Peterson 2005, Lieschke \& Currie 2007, Sullivan \& Kim 2008, Kanther \& Rawls 2010).

With all of these research areas there is a need to use fish that are SPF or at least have a comprehensive disease and pathogen history (Kent et al. 2009). For example, Vojtech et al. (2009) stated that they used SPF zebrafish for studies with Francisella, but did not state for which pathogens they were SPF. The concept of certification of pathogen-free stocks has been a mainstay in the salmonid industry, particularly where there is transport of fish between geographic regions (Stead \& Laird 2002, Kent \& Kieser 2003). This is facilitated by 
using SPF eggs when moving fish into new facilities. Indeed, egg-laying fish provide an advantage over live-bearing fish and mammals in that pathogen exposure to the next generation can be reduced by separating eggs from their parents and disinfecting them before introduction into another facility. The general rearing practice for zebrafish in research is to introduce new stocks via chlorine surface-disinfected eggs. This allows for the possibility of applying the same principles and methods routinely used in salmonid aquaculture for establishing SPF stocks, such as screening broodstock, eggs, sex products, and rearing fry in an environment completely separate from potentially infected fish, including broodstock.

The most important and widespread pathogens of zebrafish in research facilities are Pseudoloma neurophilia and Mycobacterium spp. The former is the most common pathogen in zebrafish facilities. Based on over $10 \mathrm{yr}$ of data from the Zebrafish International Resource Center diagnostic service (zebrafish.org/ zirc/health/index.php), P. neurophilia has been found in over $50 \%$ of the zebrafish facilities. Various lines of evidence suggest that the microsporidium is maternally transferred, either within or outside eggs. Spores are found within the ovary (Kent \& Bishop-Stewart 2003), and we have also found it within developing follicles. The spores of this parasite are resistant to chlorine used at the levels for treating zebrafish eggs and fry are very susceptible to the infection (Ferguson et al. 2007). Also, there are neither treatments nor vaccines available for this infection. We therefore decided that $P$. neurophilia would be a good candidate pathogen for establishing SPF populations at a new zebrafish laboratory at the Sinnhuber Aquatic Research Laboratory (SARL), Oregon State University (OSU).

\section{MATERIALS AND METHODS}

Development of SPF fish. In 2007, a new zebrafish facility was built at the SARL, OSU. As this facility had never held zebrafish, it provided the appropriate situation to attempt to establish a SPF colony of zebrafish. Moreover, the brood fish that were to be the source for the new facility were held in R. Tanguay's laboratory in another building on the OSU campus (Weniger Hall). Most of the lines were transported to OSU from University of Colorado Health Sciences Center, Denver, Colorado, USA, with R. Tanguay when he moved to the former location in 2003. All lines were originally obtained from the researchers who developed them as cited below. Our previous testing of various fish from his facility showed no Pseudoloma neurophilia infections. Therefore, they provided an ideal source for establishing SPF populations. The protocol for screen- ing and handling brood and their progeny fish destined for SARL was as follows.

Brood fish: Adult fish were fish spawned as individual pairs or in small groups using traditional spawning containers with plastic grid inserts to collect eggs (Westerfield 2007). The goal was to obtain at least 1000 eggs from the pairs or groups. This often required spawning the same fish 2 or 3 times. In this case, brood fish were held in separate aquaria and spawned at 2 to 3 wk intervals.

Eggs and fry: Eggs were collected, surface disinfected with chlorine at $50 \mathrm{ppm}$ for $5 \mathrm{~min}$, and transferred to hatching water that had been sterilized with an autoclave and contained methylene blue at $0.5 \mu \mathrm{g}$ $\mathrm{l}^{-1}$ (Westerfield 2007). Larvae were held in static water in $500 \mathrm{ml}$ beakers in a temperature controlled $\left(28^{\circ} \mathrm{C}\right)$ isolation room that had no other fish. Each group of 1000 fry derived from the same parents, even if from multiple spawns, was considered a separate family. Fry were fed paramecium for the first $2 \mathrm{wk}$, then brine shrimp nauplii and commercial diet. Using terminal procedures, 258 fry (whole fish) from the family at $10 \mathrm{~d}$ post fertilization (dpf) and the brains of all the parents were screened for Pseudoloma infection using the PCR test developed by Whipps \& Kent (2006). We were unable to obtain sufficient numbers of $A B$ brood fish from our source laboratory. Therefore, we purchased 1000 embryonated eggs of this strain from the Zebrafish International Resource Center. A total of 258 fry were screened by PCR (Whipps \& Kent 2006) and the surviving fry were transferred to the SARL.

Our sample size selection allows for detection of infection at $1 \%$ prevalence or greater with a $95 \%$ confidence (Simon \& Schill 1984; AFS-FHS 2007). If families were smaller than 1000 , we adjusted the sampling size to maintain this detection limit using tables based on the following formula:

$$
n=\left[1-(1-p)^{\frac{1}{d}}\right] \times\left[N-\left(\frac{d}{2}\right)\right]+1
$$

where $n$ is the required sample size, $N$ is population size, $p$ is the probability of finding one infected fish, usually set at $95 \%(\mathrm{p}=0.95)$, and $d$ is the minimum number of infected fish expected given a presumed prevalence $(P)$ so that $d=P \times N$. If all samples were negative, then the remaining fry were transferred to the SARL.

Husbandry and biosecurity at the SARL. Facility design: The SARL utilizes a recirculating water system. The water source is well water, charcoal filtered, particulate filtered, and UV treated at target $30000 \mu \mathrm{Ws} \mathrm{cm}{ }^{-2}$. The incoming water is then the filtered by reverse osmosis (RO), and discharged to the sump of the recirculating system. All waste water is filtered through a particulate bead filer, a fluidized biofil- 
ter, and a $10 \mu \mathrm{m}$ bag filter and then passed through biological UV treatment (100000 $\mathrm{WW} \mathrm{cm}^{-2}$ ) before it is returned to aquaria holding zebrafish. Hardness in the system is 80 to $120 \mathrm{ppm}$, conductivity is 575 to $625 \mu \mathrm{S}$ $\mathrm{cm}^{-1}$, and temperature is maintained at $28^{\circ} \mathrm{C}$. Fish are housed in one room and maintained in 13 racks with a capacity of approximately 1300 tanks (Aquaneering).

Diet: Larval fish were initially fed paramecium Paramecium caudatum as a first diet but were switched to a completely artificial diet regime starting 15 October 2009. With paramecium, $5 \mathrm{dpf}$ fish were fed $100 \mathrm{ml}$ of paramecium and 1 scoop of Zeigler Larval AP100 $<100 \mu \mathrm{m} 3$ times d $^{-1}$ until 10 dpf. Fish reared without paramecium were fed as follows. At $5 \mathrm{dpf}$, fish were given a diet consisting of equal parts of Zeigler Larval AP100 <100 $\mu \mathrm{m}$, Golden Pearls 100 to $200 \mu \mathrm{m}$ (Brine Shrimp Direct) and Freeze Dried Rotifers 100 to $200 \mu \mathrm{m}$ (Brine Shrimp Direct,). Then at 10 to $21 \mathrm{dpf}$, fish were fed Artemia nauplii and powdered diet (50\% Zeigler Larval AP100 <100 $\mu \mathrm{m}$ and 50\% Zeigler Larval AP100 150 to $250 \mu \mathrm{m}) 3$ times per day. At 22 to $45 \mathrm{dpf}$, fish were fed Artemia nauplii and powdered diet $(50 \%$ Zeigler Larval AP100 150 to $250 \mu \mathrm{m}$ and 50\% Zeigler Larval AP100 250 to $450 \mu \mathrm{m}) 3$ times per day. At 45 to $60 \mathrm{dpf}$, fish were fed as 22 to $45 \mathrm{dpf}$ in the morning and midday and Artemia nauplii and adult flake in the evening.

Personnel access and staff procedures: To avoid potential transmission of waterborne pathogens between tanks, separate nets are used for each tank. Nets are disinfected by washing in the lab dishwasher using Neodisher detergent and neutralizer (Chemische Fabrik Dr. Weigert) and the nets are then hung until completely dry before the next use. Staff, visitors, etc. are allowed into the facility for specific reasons only and only with prior approval by the laboratory manager and/or Dr. Tanguay. Staff working in the main facility are not allowed to have contact with other zebrafish populations. All staff must wash their hands thoroughly before entering the room. Protective footwear (disposable booties or designated non-disposable shoes or boots must be worn). No one is allowed in the animal room without strict supervision until they have been trained and have shown proficiency with each component of the biosecurity program. Staff are given a written copy of the biosecurity protocol, and senior staff oversees new staff and students to assure they are competent at implementing biosecurity rules.

Retraining occurs as needed, based on observation of senior staff. Visitors and staff are not allowed into the animal room if they have come in contact with other live fish the same day. If they must visit or work in other labs, this is done after working in the SPF facility and staff are not allowed to return to the main facility that day.
Health monitoring. Fish at the SARL were routinely monitored for the presence of Pseudoloma neurophilia using both PCR and histology. Histology was also used to document other infections and histological changes. For histology, fish were preserved in Deitrich's fixative and processed for routine histology. Midline sagittal sections were prepared so that a large portion of the brain and spinal cord was present. Slides were then stained with hematoxylin and eosin or Accustain Gram stain (Sigma-Aldrich). Additional sections were stained with Fite's Acid Fast for any fish that exhibited histological changes suggestive of mycobacteriosis.

For PCR, either whole fish (larvae) or brains (juveniles and adults) were frozen, and screened using a conventional PCR test (Whipps \& Kent 2006). Starting 1 November 2008 we switched to a new, quantitative PCR test recently developed in our laboratory (Sanders $\&$ Kent 2011). The program for these examinations was as follows.

Moribund or dead fish: Dead or moribund fish were saved for histology. External, macroscopic changes were noted. To assure proper fixation, the body cavity was exposed by a cut in the abdominal wall and then fish were placed in individual tubes.

Routine screening of existing lines: Each line at the SARL was regenerated on a 4 mo rotation. For each of these major propagations, a subsample was screened for Pseudoloma neurophilia. Sixty fry from the large pool (e.g. 500 to 2000 fry) were collected randomly at $10 \mathrm{~d}$ post hatch. Fry are pooled in groups of 10 and screened by PCR for P. neurophilia.

Retired populations: Brood fish from each line were retired and euthanized at approximately $1 \mathrm{yr}$ of age. Twenty fish were examined by histology and the brains and spinal cords of 60 fish were combined in pools of 5 and screened by PCR.

Sentinel program: The sentinel program at the SARL consists of holding eighty 4 mo old 5Ds in 4 sentinel tanks (20 per tank) and $80 \mathrm{ABs}$ in 4 sentinel tanks (20 per tank). Description of lines is given in the 'Results'. These tanks were placed so that they receive effluent water from all tanks prior to filtration in the main room. Fish were fed daily as in main room. Fish were exposed for 3 to 4 mo and then replaced with the next generation of 5Ds and ABs. Twenty fish were examined by histology and the brains of another 60 fish (in pools of 5) were screened by PCR for Pseudoloma neurophilia.

\section{RESULTS}

Between April 2007 and July 2009 we successfully screened and transferred 9 populations, representing the following lines: Tg(isl1:GFP), Higashijima et al. (2000); Tg(HuC:GFP), Higashijima et al. (2003); 
Tg(NBT:MAPT-GFP, (gift from Chien Laboratory, University of Utah); Tg(fli1a:EGFP)y1, Lawson \& Weinstein (2002); AB (developed at University of Oregon); 5D, an outbred stock developed from fish that we obtained from 5D Tropical Plant City Florida; Tg(8.4neurog1:GFP), Blader et al. (2004); Tg(hsp70:tcf3-GFP)w26, Lewis et al. (2004); and MPO (Tg(mpx:GFP)i113), Renshaw et al. (2006). This represented a total of 2203 fish transferred to the SARL, which were designated $\mathrm{F}_{0}$. During our screening, we found positive fish in one population, called Islets, from the source laboratory (Weniger Hall) for Pseudoloma neurophilia by PCR. Brood fish from this population were spawned May 2007 and 4 of 7 fish were also positive by histological examination. $F_{1} S$ from this group, also held at the source laboratory, were also positive by both PCR and microscopy. Fortunately, another population of Islets held at Weniger Hall was available. Thirteen of these fish were spawned in a group spawn (Lawrence 2007, Westerfield 2007) and their fry were screened, found to be negative, and were transferred to the SARL following the protocol described above.

Adults and progeny of another line from the source laboratory, called Blingless (purchased from Znomics) were positive for Pseudoloma neurophilia. Unfortunately, other populations were not available, and thus this line was not established at the SARL. The various lines at Weniger came from Dr. Tanguay's laboratory at the University of Wisconsin and were transferred to Weniger in 2002, except for Blingless and Islets, which came from 2 other laboratories.

As of 15 July 2010, we had evaluated 2800 adult fish by PCR and 1222 fish by histology from subsequent generations at the SARL that were clinically normal, moribund or deformed fish from the sentinel program or a toxicology study. This represents 25 retired fish groups $(\mathrm{PCR}=1500$, histology $=58)$, 3 sentinel groups $(\mathrm{PCR}=180$, histology $=58), 10$ moribund fish (histology only), and over 700 clinically normal fish from a toxicology study (histology only) conducted at SARL. The toxicology study represented fish from 2 separate experiments in which larval fish were exposed continuously to a toxicant starting at $12 \mathrm{~d}$ post hatch and reared for $4 \mathrm{mo}$. Controls and fish exposed to various levels of the undisclosed toxicant were examined by histology at the end of each experiment. In addition, a total of 112010 -d old fry from 19 populations were assayed by PCR.

No fish exhibited histological changes consistent with Pseudoloma neurophilia and all fish that we examined by PCR were negative for the parasite. The AB line was the first group transferred to the SARL in April 2007. These fish exhibited chronic mortality and survivors grew poorly. Histological examination of 10 moribund fish that had been in the facility for over 1 mo exhibited severe hepatic megalocytosis (Fig. 1). As this lesion is associated with toxicant exposure, it was surmised that a toxicant from the plastics in the new recirculating water system was leaching into the water. Therefore, a charcoal filter was added to the system and subsequent examinations of both moribund and sentinel fish showed no more dramatic liver changes. Subsequently, one individual fish from 6 different groups of retired fish and one sentinel fish exhibited mild to moderate hepatic megalocytosis (Fig. 1).

Mycobacteriosis was detected in a few fish from all categories (Table 1). Aside from the moribund fish described above, all fish with this disease appeared clinically normal. Histological examination of these fish showed a variety of lesions consistent with mycobacteriosis, including chronic coelomitis, aerocystitis, or oophoritis. Multiple granulomas or more diffuse, chronic inflammatory lesions were observed in the liver, kidney, pancreas, swim bladder or ovaries (Fig. 1). Diagnosis was confirmed by observation of acid-fast bacteria in sections stained with Fite's acid fast. Mycobacteriosis was significantly higher in the retired fish $(3.8 \%)$ than those in the toxicology experiments $(0.7 \%)$ (Fisher's Exact Test, p > 0.001).

Several other fish exhibited chronic inflammatory lesions in the mesenteries or visceral organs in which acid-fast bacteria were not visualized. In addition, egg associated inflammation and fibroplasia, characterized by chronic oophoritis was seen in several females (Fig. 1). One moribund Islet fish had a cholangiocellular carcinoma that replaced almost the entire liver parenchyma (Fig 1). A spermatocytic seminoma was observed in one retired male fli strain fish, and one retired female also had a large spermatocytic semi- 


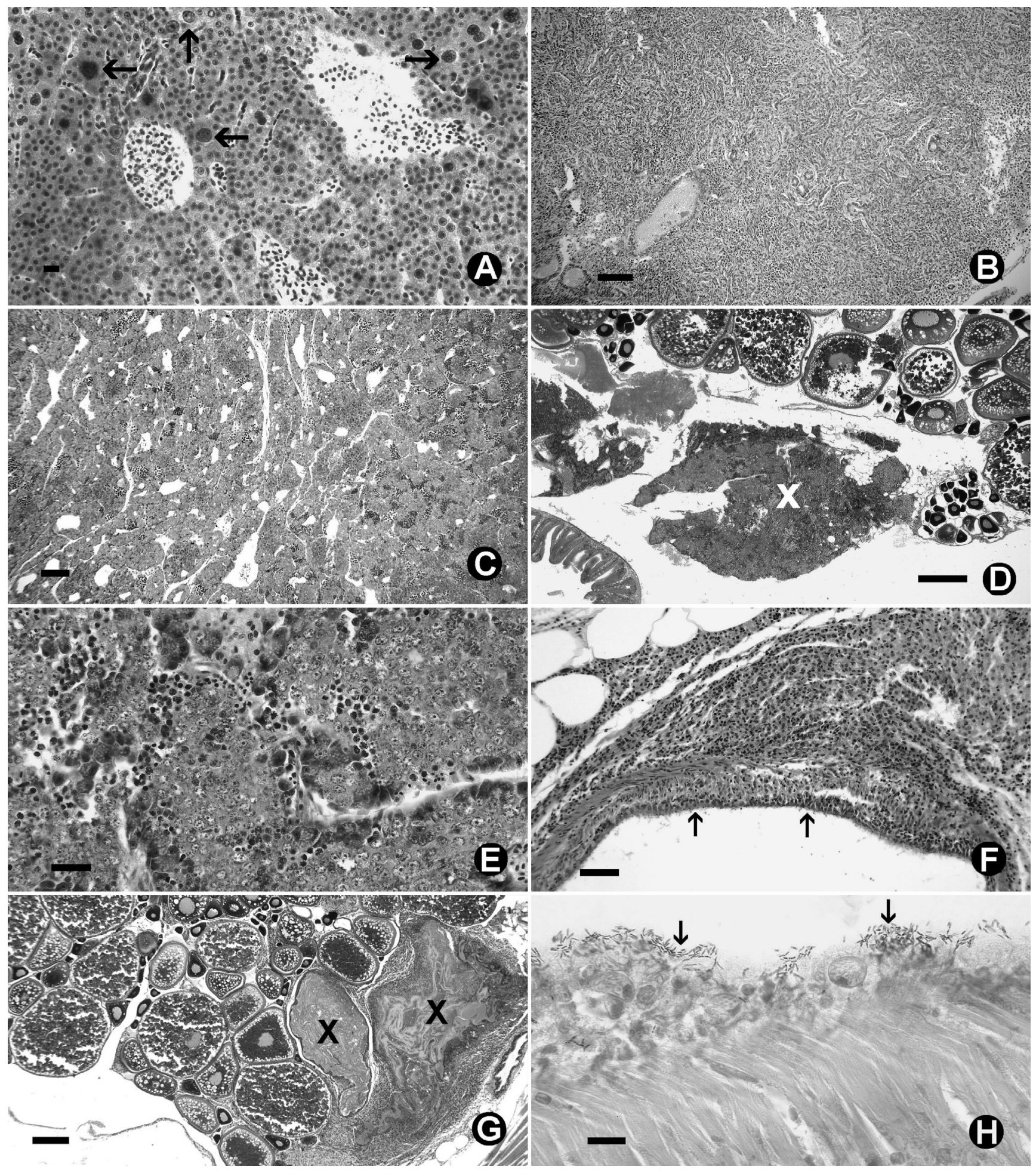

Fig. 1. Danio rerio. Histological sections of zebrafish from a specific pathogen-free (SPF) colony. (A) Severe hepatocytic megalocytosis, with enlarged nuclei (arrows) and hepatocytes. (B) Cholangiocellular carcinoma replacing entire liver parenchyma. (C) Spermacytic seminoma. (D) Ovotestes; X: seminoma in mesenteries adjacent to mature ovaries. (E) High magnification of seminoma from fish with ovotestes. (F) Chronic aerocystitis. Arrows: bacteria lining surface of swim bladder epithelium. (G) Oophoritis (egg-associated inflammation and fibroplasia); X: raft of eosinophilic yolk debris and fibroplasia. (H) Swim bladder surface with acid bacteria (arrows). Scale bars: $(A, H)=10 \mu \mathrm{m},(B, C)=100 \mu \mathrm{m},(F)=50 \mu \mathrm{m},(E)=25 \mu \mathrm{m},(D, G)=500 \mu \mathrm{m}$. Staining: (A-G) hematoxylin and eosin, (H) Fite's acid fast 
noma that arose within pancreatic tissues. This female fish had a well-developed ovary and follicles that were undergoing normal maturational development, and hence the diagnosis was ovotestes.

\section{DISCUSSION}

After 3 yr in operation, Pseudoloma neurophilia has not been detected in this facility based on the examination of over 3000 fish composed of multiple generations of moribund, sentinel, fry, retired broodstock, and fish used in experiments. While morbidity and mortality has been minimal, we have detected some lesions in fish. Hepatic megalocytosis in fish is associated with exposure of both natural and anthropogenic toxicants. We concluded that these liver lesions seen in the first group of $A B$ line were caused by toxicants released from the new plastic tanks, pipes, and possibly a soft plastic bladder in the system. Following addition of a charcoal filter, severe hepatic megalocytosis was not observed. However, it was not know if this corrected the problem or if the putative toxicant was removed over time merely by leeching of the plastics. Mild forms of hepatic megalocytosis and other related toxicopathic lesions are actually rather common in zebrafish facilities. Microcystin, produced by freshwater cyanobacteria, causes similar changes in fish (Andersen et al. 1993), and it is possible that a natural toxin produced by bacteria, fungi or algae may be the cause of these lesions. Spitsbergen \& Kent (2003) noted that hepatic megalocytosis was particularly common in recirculating systems using fluidized sand filters.

Mycobacteriosis was observed in a few fish. This is the second most common disease in zebrafish facilities (Astrofsky et al. 2000, Kent et al. 2004). Unlike Pseudoloma neurophilia, which is an obligate intracellular parasite, some Mycobacterium spp. (e.g. M. chelonae) are ubiquitous in freshwater and proliferate outside of the host. Hence, it would be more difficult to establish an SPF zebrafish colony for Mycobacterium spp. in general. The infection was only diagnosed by histopathology and thus the species infecting these fish was not determined. There was over 5 times the prevalence of mycobacteriosis in the retired fish than in the toxicology experiments. The retired fish were about $1 \mathrm{yr}$ old, while those from the toxicology study were euthanized at when they were 4 mo old. Incidents of mycobacteriosis increase with age in other animals, including fish (Gauthier et al. 2008), which provides an explanation for this difference. Therefore, one approach to reduce mycobacteriosis in zebrafish colonies would be to retire brood stock at an earlier age when feasible. Acid-fast bacteria were not observed in several fish with lesions that were consistent with myco- bacteriosis, such as chronic coelomitis, aerocystitis or oophoritis. All of these lesions have been associated with mycobacteriosis in zebrafish (Kent et al. 2004, Whipps et al. 2008), but can be due to other causes. For example, chronic oophoritis, referred to as egg-associated inflammation, is thought to be caused by egg retention in fish that are not spawned on a regular basis. Conversely, absence of detection of acid-fast bacteria in tissue sections does not confirm absence of Mycobacterium spp. (Canale et al. 2000).

It should be easier to establish SPF fish in zebrafish research facilities compared to larger aquaculture endeavors as they use pathogen-free incoming water, utilize high doses of UV in recirculating systems, and introduce fewer fish to main facilities at a given time. One negative factor with many zebrafish facilities is that, unlike mouse colonies, breeding colonies are housed in the same rooms as research fish and that staff (including inadequately trained students) often have unrestricted access to both.

Appropriate education of personnel is essential as many of the staff responsible for zebrafish care have little formal training in control of infectious diseases. These individuals also often maintain home aquaria and thus have contact with other fish species. The recent observation of Pleistophora hyphessobryconis (Microsporidia) in zebrafish research colonies (Sanders et al. 2010) exemplifies the risk of aquarium fish pathogens to zebrafish in a laboratory setting. The zebrafish community should consider protocols as used by the mice community for controlling and avoiding pathogens. For example, most SPF mouse facilities do not allow technicians working with the mice to be in contact with rodents outside the facility, including home pets. Perhaps a protocol this extreme is not required with zebrafish, as presumably fish pathogens are not as easily transmitted as those in a terrestrial environment. However, it is reasonable to require staff and visitors to thoroughly wash their hands before entering facilities and ensure the existence of other biosecurity measures to prevent the movement of water or other wet material into a restricted laboratory.

Pleistophora hyphessobryconis may be another candidate to screen for using the methods described here. To date, no viral diseases have been detected in zebrafish facilities, but once they are identified, a similar approach as we have employed here could be implemented. Now we are distributing limited numbers of these SPF fish through a collaboration with the Zebrafish International Resource Center at the University of Oregon, Eugene.

Acknowledgements. This project was supported by grants from the National Institutes of Health NCRR 5R24RR01738602 and 1 T32 RR023917, and NIEHS P30 ES000210. 


\section{LITERATURE CITED}

AFS-FHS (American Fisheries Society-Fish Health Section) (2007) FHS blue book: suggested procedures for the detection and identification of certain finfish and shellfish pathogens, AFS-FHS, Bethesda, MD

Andersen RJ, Luu HA, Chen DZX, Holmes CFB and others (1993) Chemical and biological evidence links microcystin to salmon 'netpen liver disease'. Toxicon 31:1315-1323

Astrofsky KM, Schrenzel MD, Bullis RA, Smolowitz RM, Fox JG (2000) Diagnosis and management of atypical Mycobacterium spp. infections in established laboratory zebrafish (Brachydanio rerio) facilities. Comp Med 50: 666-672

Blader P, Lam CS, Rastegar S, Scardigli R and others (2004) Conserved and acquired features of neurogenin1 regulation. Development 131:5627-5637

Canale G, Spa C, Bannister BB, Begg NT (2000) Tuberculosis and other mycobacterial diseases. In: Bannister B, Begg NT, Gillespie SH (eds) Infectious disease. Blackwell Scientific Publications, Oxford, p 337-360

Ferguson JA, Watral V, Schwindt AR, Kent ML (2007) Spores of two fish Microsporidia (Pseudoloma neurophilia and Glugea anomola) are highly resistant to chlorine. Dis Aquat Org 76:205-214

Fishman MC (2001) Genomics. Zebrafish-the canonical vertebrate. Science 294:1290-1291

Gauthier DT, LaTour RJ, Heisey DM, Bonzek CF, Gartland J, Burge EJ, Vogelbein WK (2008) Mycobacteriosos-associated mortality in wild striped bass (Morone saxatilis) from Chesapeake Bay, USA. Ecol Appl 18:1718-1727

> Higashijima S, Hotta Y, Okamoto H (2000) Visualization of cranial motor neurons in live transgenic zebrafish expressing green fluorescent protein under the control of the islet1 promoter/enhancer. J Neurosci 20:206-218

Higashijima S, Masino MA, Mandel G, Fetcho JR (2003) Imaging neuronal activity during zebrafish behavior with a genetically encoded calcium indicator. J Neurophysiol 90:3986-3997

Kanther M, Rawls JF (2010) Host-microbe interactions in the developing zebrafish. Curr Opin Immunol 22:10-19

Kent ML, Bishop-Stewart JK (2003) Transmission and tissue distribution of Pseudoloma neurophilia (Microsporidia) of zebrafish Danio rerio. J Fish Dis 26:423-426

Kent ML, Kieser D (2003) Avoidance of introduction of exotic pathogens with Atlantic salmon reared in British Columbia. In: Lee CS, O'Bryen PJ (eds) Biosecurity in aquaculture production systems: exclusion of pathogens and other undesirables. World Aquaculture Society, Baton Rouge, LA, p 43-50

Kent ML, Matthews JL, Bishop-Stewart JK, Whipps CM, Watral V, Poort M, Bermudez L (2004) Mycobacteriosis in zebrafish (Danio rerio) research facilities. Comp Biochem Physiol C Toxicol Pharmacol 138:383-390

Kent ML, Feist SW, Harper C, Hoogstraten-Miller S and others (2009) Recommendations for control of pathogens and infectious diseases in fish research facilities. Comp Biochem Physiol C Toxicol Pharmacol 149:240-248

Editorial responsibility: David Marcogliese, Montreal, Quebec, Canada
Lawrence C (2007) The husbandry of zebrafish (Danio rerio): a review. Aquaculture 269:1-20

Lawson ND, Weinstein BM (2002) In vivo imaging of embryonic vascular development using transgenic zebrafish. Dev Biol 248:307-318

> Lewis JL, Bonner J, Modrell M, Ragland JW, Moon RT, Dorsky RI, Raible DW (2004) Reiterated Wnt signaling during zebrafish neural crest development. Development 131:1299-1308

Lieschke GJ, Currie PD (2007) Animal models of human disease: zebrafish swim into view. Nat Rev Genet 8:353-367

Renshaw SA, Loynes CA, Trushell DM, Elworthy S, Ingham PW, Whyte MK (2006) A transgenic zebrafish model of neutrophilic inflammation. Blood 108:3976-3978

Sanders JL, Kent ML (2011) Development of a sensitive assay for the detection and quantification of Pseudoloma neurophilia in laboratory populations of the zebrafish Danio rerio. Dis Aquat Org (in press)

Sanders JL, Lawrence C, Nichols DK, Brubaker JF, Peterson TS, Murray KN, Kent ML (2010) Pleistophora hyphessobryconis (Microsporidia) infecting zebrafish Danio rerio in research facilities. Dis Aquat Org 91:47-56

Simon RC, Schill WB (1984) Tables of sample size requirements for detection of fish infected by pathogens: three confidence levels for different infection prevalence and various population sizes. J Fish Dis 7:515-520

Spitsbergen JM, Kent ML (2003) The state of the art of the zebrafish model for toxicology and toxicologic pathology research-advantages and current limitations. Toxicol Pathol 31(Suppl):62-87

Stead SM, Laird LM (2002) Handbook of salmon farming. Springer Verlag, New York, NY

Sullivan C, Kim CH (2008) Zebrafish as a model for infectious disease and immune function. Fish Shellfish Immunol 25: 341-350

Sumanas S, Lin S (2004) Zebrafish as a model system for drug target screening and validation. Drug Discov Today: TARGETS 3:89-96

- Traver D, Winzeler A, Stern HM, Mayhall EA and others (2004) Effects of lethal irradiation in zebrafish and rescue by hematopoietic cell transplantation. Blood 104: 1298-1305

Vojtech LN, Sanders GE, Conway C, Ostland V, Hansen JD (2009) Host immune response and acute disease in a zebrafish model of Francisella pathogenesis. Infect Immun 77:914-925

Westerfield M (2007) The zebrafish book, 5th edn. A guide for the laboratory use of zebrafish (Danio rerio). University of Oregon Press, Eugene, OR

Whipps CM, Kent ML (2006) Polymerase chain reaction detection of Pseudoloma neurophilia, a common microsporidian of zebrafish (Danio rerio) reared in research laboratories. Contemp Top Lab Anim Sci 45:13-16

> Whipps CM, Matthews JL, Kent ML (2008) Distribution and genetic characterization of Mycobacterium chelonae in laboratory zebrafish Danio rerio. Dis Aquat Org 82:45-54

Zon LI, Peterson RT (2005) In vivo drug discovery in the zebrafish. Nat Rev Drug Discov 4:35-44

Submitted: September 27, 2010; Accepted: January 11, 2011

Proofs received from author(s): April 21, 2011 